\title{
SUGAR-FREE CONFUSION NOT SWEET FOR TEETH
}

Sugar may be one of the hottest topics in the news, but a new survey has shown a desperate need for better sugar education as Britons think chocolate, sweets and fruit juice contain no sugar.

A survey of more than $2,000^{1}$ people carried out by Denplan revealed one in five people (21\%) don't believe chocolate contains sugar, with the same amount (22\%) thinking biscuits are sugar-free too. Drinks are not immune from sugar ignorance either, with almost half (47\%) of respondents believing that neither wine or beer contain sugar. Perhaps more worryingly, over a third (38\%) of people asked did not know that fruit juice contained sugar, despite warnings from Action on Sugar that many juices contain at least six teaspoons of sugar - more than cola. ${ }^{2}$

Other food and drinks which respondents believed were free of sugar included:
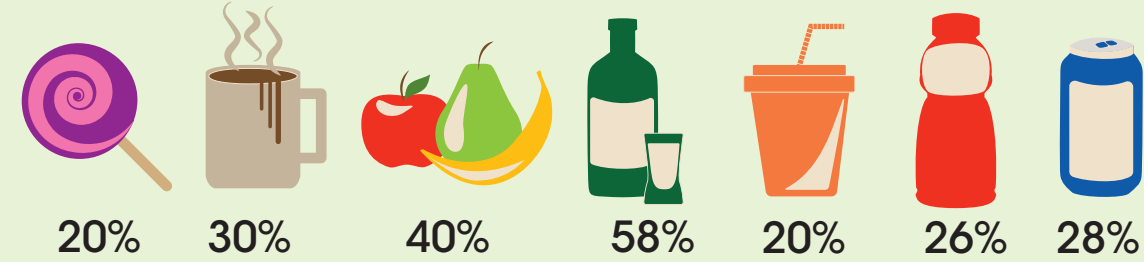

Sweets

Hot chocolate

\section{$40 \%$}

$58 \%$

$20 \%$

$26 \%$

$28 \%$

Sports drinks

Energy

The new results also showed the public's desire for more clarity on labelling of products, as $54 \%$ admitted that they wanted to reduce their sugar consumption, but just one in five respondents could decipher whether a product contains sugar by reading ingredient labels. $80 \%$ said they don't always check the list of ingredients before buying or eating food, and over a third of respondents (38\%) said they didn't know the difference between 'sugar-free' and 'no added sugar'.

Henry Clover, Deputy Chief Dental Officer at Denplan said: 'With sugar 'hidden' in so many unexpected foods and drinks, managing our daily sugar consumption can be a challenge.'

1. A Onepoll survey of 2,000 participants conducted in May 2015

2. http://www.bbc.co.uk/news/health-29986012 